\title{
The Rhythm of Conceptions. Seasonality of Births in Taiwan and the Netherlands, 1800-1940
}

\section{By Theo Engelen}

To cite this article: Engelen, T. (2021). The Rhythm of Conceptions. Seasonality of Births in Taiwan and the Netherlands, 1800-1940. Historical Life Course Studies, 10, 86-90. https://doi.org/10.51964/hlcs9573

\section{HISTORICAL LIFE COURSE STUDIES}

Not Like Everybody Else.

Essays in Honor of Kees Mandemakers

VOLUME 10, SPECIAL ISSUE 3

2021

\section{GUEST EDITORS}

Hilde Bras

Jan Kok

Richard L. Zijdeman 


\section{HISTORICAL LIFE COURSE STUDIES}

Historical Life Course Studies is the electronic journal of the European Historical Population Samples Network (EHPSNet). The journal is the primary publishing outlet for research involved in the conversion of existing European and nonEuropean large historical demographic databases into a common format, the Intermediate Data Structure, and for studies based on these databases. The journal publishes both methodological and substantive research articles.

\section{Methodological Articles}

This section includes methodological articles that describe all forms of data handling involving large historical databases, including extensive descriptions of new or existing databases, syntax, algorithms and extraction programs. Authors are encouraged to share their syntaxes, applications and other forms of software presented in their article, if pertinent, on the openjournals website.

\section{Research articles}

This section includes substantive articles reporting the results of comparative longitudinal studies that are demographic and historical in nature, and that are based on micro-data from large historical databases.

Historical Life Course Studies is a no-fee double-blind, peer-reviewed open-access journal supported by the European Science Foundation (ESF, http://www.esf.org), the Scientific Research Network of Historical Demography (FWO Flanders, http://www.historicaldemography.be) and the International Institute of Social History Amsterdam (IISH, http://socialhistory.org/). Manuscripts are reviewed by the editors, members of the editorial and scientific boards, and by external reviewers. All journal content is freely available on the internet at https://openjournals.nl/index.php/hlcs.

\section{Co-Editors-In-Chief:}

Paul Puschmann (Radboud University) \& Luciana Quaranta (Lund University)

hislives@kuleuven.be

The European Science Foundation (ESF) provides a platform for its Member Organisations to advance science and explore new directions for research at the European level. Established in 1974 as an independent non-governmental organisation, the ESF currently serves 78 Member Organisations across 30 countries. EHPS-Net is an ESF Research Networking Programme.

The European Historical Population Samples Network (EHPS-net) brings together scholars to create a common format for databases containing non-aggregated information on persons, families and households. The aim is to form an integrated and joint interface between many European and non-European databases to stimulate comparative research on the micro-level.

Visit: http://www.ehps-net.eu.
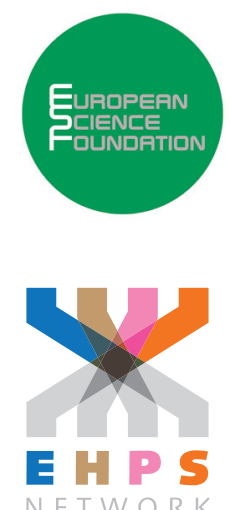


\section{The Rhythm of Conceptions}

\section{Seasonality of Births in Taiwan and the Netherlands, 1800- 1940}

Theo Engelen

Radboud University Nijmegen

\section{ABSTRACT}

The seasonality of births provides us with insights into the economic, cultural, and biological effects on the private lives of our predecessors in time. This comparison between two culturally very different societies results in the conclusion that there is an amazing geographic and historical stability in the patterns of seasonality in conceptions, both in Taiwan and in the Netherlands. Economic and cultural variables only have a minor influence. The fact that a biological variable like temperature is so dominant in the Taiwanese case suggests that future studies may benefit from focusing more on the biological determinants of human behaviour.

Keywords: Seasonality, Fertility, Historical demography, Taiwan, The Netherlands

e-ISSN: $\quad$ 2352-6343

DOI article: $\quad$ https://doi.org/10.51964/hlcs9573

The article can be downloaded from here.

This open-access work is licensed under a Creative Commons Attribution 4.0 International License, which permits use, reproduction \& distribution in any medium for non-commercial purposes, provided the original author(s) and source are given credit. See http://creativecommons.org/licenses/. 


\section{INTRODUCTION}

Few historical disciplines offer such intimate information on the lives of our predecessors in time as historical demography. Data on births, marriages, deaths and to a lesser extent migration are available for many centuries and - contrary to most other sources - on the whole population rather than on the ruling classes only. In this paper I will focus on the seasonality of births in the Netherlands during the long 19th century, 1800-1940, and Taiwan during the Japanese occupation, 1900-1944. The aim is to present a description of the form this seasonality took, the development of the phenomenon in time, the differences between parts of the two countries, and, lastly, to find out what influences determined both the basic form and the deviations of the seasonality pattern. The comparison between two culturally diverse populations hopefully offers extra insights in the background of the fertility seasonality.

We have to keep in mind, though, that a birth at a given date is not the actual object of study, because this is only the consequence of behavior approximately 280 days before that date. When looking at the seasonality of births, we are actually interested in the seasonality of conceptions, and thus we are actually studying human sexuality and fecundity. The obvious first question then is whether or not the frequency of intercourse differs throughout the year. Next, before intercourse can result in a birth nine months later, a conception has to take place, and this depends on the fecundity of the male and the female partner. Again, the fecundity itself is dependent on pure biological variables, but may be influenced by circumstances like weather and workload. We therefore have to look into variables that influence both elements of a conception, namely intercourse and fecundity. It will be interesting to see whether both populations share the same determinants.

\section{HISTORIOGRAPHY}

Let us start with the findings that researchers seem to agree upon: all studies on western societies indicate that after being very strong in pre-industrial times, during the 20th century the seasonality of births became less visible (among many others: Doblhammer, Rodgers, \& Rau, 2000). The same conclusion was reached for Taiwan by Anderton and Barrett (1990).

In the explanation for the seasonality pattern of births we find contradicting positions. The explanation consists of two groups of variables. First, we have the behavioral or socio-cultural determinants, like religious prescriptions, cultural norms and socio-economic constraints. Next to this, many authors studied the biological or environmental variables, like nutrition and temperature.

The notion on the influence of nutrition is rather straightforward. Food availability fluctuates during the year, especially in historical societies. Immediately after the harvest the abundance of food was guaranteed, but in the months before the new harvest populations often had to deal with inadequate food intake. The effect is reported on for African populations: 'A very important determinant of the female ovarian function (read fecundity) is the energetic intake. Gestation and lactation place a heavy burden. Relatively modest changes in weight produce significant changes in the probability of conception. Logically, when ecological constraints on availability of food are of a seasonal nature, this can result in seasonality of births.' (Ellison, Valeggia, \& Sherry, 2005). In his study of a rural Taiwan fishing community in the period 1926-1976, Mosher (1979) also strongly argued that the annual cycle of production, through diet, caused the seasonality of births (= conceptions). He saw a direct influence of nutrition on human fertility.

On the influence of temperature there is more debate. Although in many cases a negative association between high temperatures and the number of conceptions is established, there is still uncertainty on the way this link works. Some authors point at the deterioration of sperm quality or the suppression of ovulation as a result of high temperatures, but others deny this effect. All authors seem to agree on another result of summer heat, the so-called comfort factor. High temperatures are simply discouraging to coitus (Ellison et al., 2005). Since the Netherlands clearly has a temperate climate, we do not expect summer heat to have an influence on the seasonality of conceptions. In Taiwan, on the other hand, hot summers were frequent. Studies confirmed that climate regulated the monthly distribution rather than workload or religious reasons.

The other set of explanatory variables is of a socio-cultural nature. We have to take into account, for instance, religious regulations. A study on 20th-century Romania showed the effect the interdiction of sexual 
intercourse during Advent and Lent fasting periods had on the date when babies were conceived. Religious affiliation was indeed shown to be an important factor for the date of conception. In particular, the Roman Catholic Church discouraged intercourse in the two fasting periods (Manfredini, 2009).

A Finnish study covering the period 1653-1950 argued that the variation in birth seasonality can best be explained by socio-economic differences between the regions. As a result, the variation disappeared when differences in living conditions diminished (Fellman \& Eriksson, 2009). Bobak and Gjonca (2001) found a clear influence of sociodemographic variables like age, level of education and parity of the pregnancy on birth seasonality in the Czech Republic. They expect that the more fertility is consciously controlled, the less biological influences will show. Finally, a study on developments in French seasonality after 1975 simply states that the gradual disappearance of the seasonality of births during the 20th century is due to the fact that the reasons for seasonality lost impact when religious regulations were no longer followed, marriage and fertility were less connected, food availability over the year no longer varied and the proportion of people working in agriculture declined (Régnier-Loilier, 2010).

\section{SOURCES AND QUESTIONS}

For the Dutch case, this study is based on data drawn from the Historical Sample of the Netherlands (HSN). IDS Release 2017_01 Data Set. Information on this database can be found in Mandemakers (2000). The database that makes our calculations for Taiwan possible has been constructed in the Program for Historical Demography, Academia Sinica, Taiwan, and uses the Japanese household registers. These registers contain all household members and their personal life events with dates (e.g. birth, adoption, marriage, divorce, death, temporary registration elsewhere, permanent entry into and exit from the administrative unit by migration). The registers provide not only a large population sample, but considerable demographic detail at the individual level. For this article we used the data on five fieldsites: Chupei, Lukang, Ruchuan, Tonka and Taipei. In total, the number of births included for Taiwan were 35,198 and for the Netherlands 158,000. The monthly indices for births/conceptions are calculated by controlling for the number of days in a month, and taking the average monthly number as 100 .

Given the findings in earlier research we will focus on the three factors that theoretically influence the seasonality of conceptions: economy, culture and biology. First there is the economic environment. Our data only allows us to use the position in the labour market. The question we aim to answer is whether the working load in agriculture determines the time of year when conceptions occurred. Next, the cultural determinants deserve our attention. In the Netherlands, the well-known difference between Roman Catholics and Protestants will be looked at, whereas in Taiwan ethnicity was a category of cultural identity. And, lastly, we will try to establish whether or not temperature influences the seasonality of conceptions.

\section{FINDINGS}

Looking at Graph 1 we can conclude that both populations had a distinct seasonal pattern of conceptions, but also that this pattern clearly differed. The Taiwan values show a much larger amplitude than the Dutch, with highest numbers of conceptions in the first five months followed by a remarkable decline until August. The values for the last four months once again show a rise until December. For Dutch couples, conception rates peaked in Spring and early Summer, after which a decline followed until October. The last months of the year witnessed a rising number of conceptions, building up again towards the Spring peak. Although the two graphs show a slight similarity, the most remarkable finding is the digression from the mean, the standard deviation being 14 in Taiwan and 5 in the Netherlands. 


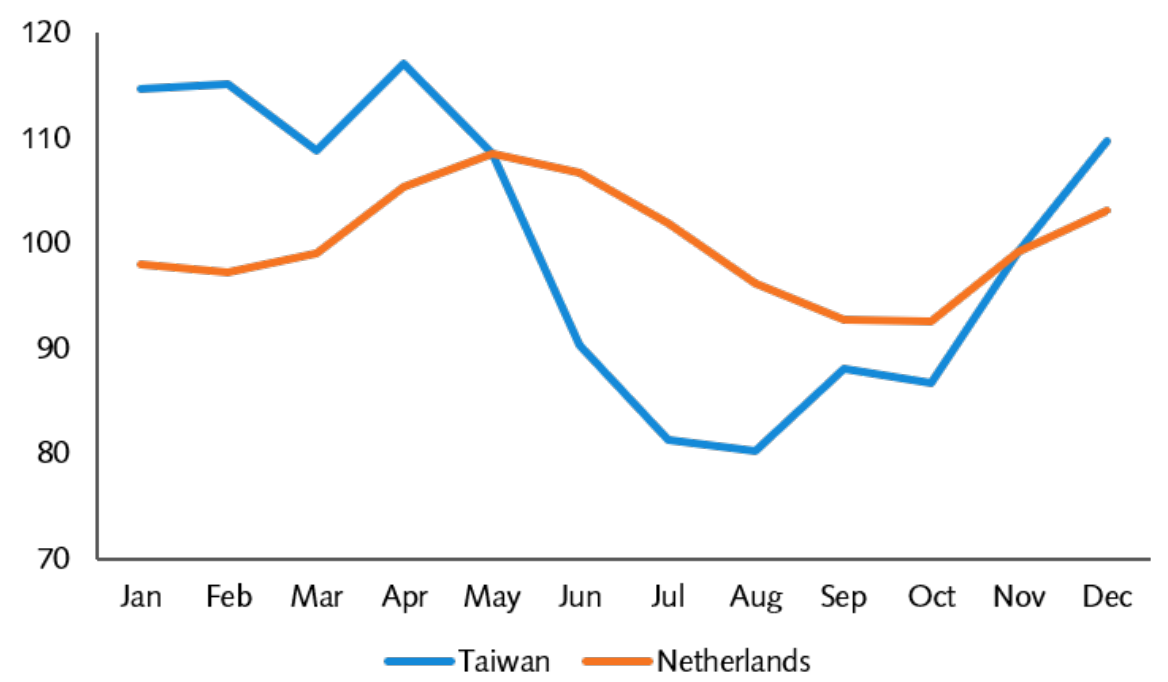

Note: Index 100 = average

For both populations, we also looked at the development in time, in Taiwan comparing the period up to and after 1920, and in the Netherlands the periods 1811-1840, 1841-1889 and 1881-1922. We find only minor changes over time. The general distribution remains the same throughout the period studied in both countries, although the amplitude grew smaller, again in both cases. When we look at the differences between the Dutch provinces and between the Taiwanese field sites the conclusion must be that we witness a small variance within the two countries, and again the basic form of the graphs remains Taiwanese or Dutch. So neither historical development nor geography seem to have been able to distort influences that shape the seasonality of conceptions. Which, of course, makes the search for crucial variables the more interesting.

Let us start with the impact of economy. Both datasets provide us with the information on the occupation of the fathers of the new-born children. We arranged these occupations according to the HISCLASS categories (van Leeuwen \& Maas, 2011). This results in a division into five categories: Elite (HISCLASS 1-2), Middle Class (HISCLASS 3-4), Skilled Worker (HISCLASS 5-7), Farmer (HISCLASS 8) and Lower/Unskilled Worker (HISCLASS 9-13).

When we arrange the conceptions per month by the major social groups we find that in both countries all categories show the same pattern, except for the elite. When calculating possible resemblances between the classes we find correlations above 0.8. Only the elite group deviates from the average. In Taiwan members of this group married exceptionally often in March and November, whereas Dutch elite couples preferred September and October.

The cultural impact of religion in the Netherlands and ethnicity in Taiwan has also been of relatively small influence. We find a very low number of conceptions among Dutch Roman Catholics in March and December. Given the rules on abstinence during Lent and Advent this is not surprising. Again, however, this is only a small deviation from the general trend. A similar conclusion goes for Taiwan. The variation between the conceptions of Hakka and Hokkien couples is small and the general pattern is present for both ethnicities. In particular, the low number of conceptions in the so-called Ghost Month (coinciding with July-August) is remarkable.

There is one biological factor that is easy to trace: temperature. We cannot discern whether the impact is through lower fecundity or through the 'comfort factor', but we can calculate the statistical relationship between temperature and the number of conceptions per month. Again, this relationship does not exist in the moderate climate zone of the Netherlands. In Taiwan, however, the predicted relationship is clear. Whenever the temperature was high, the number of conceptions was low. In general, this negative correlation amounts to 0.8. For those who do not have to work in the field, the association is less strong, being 0.56 for the Middle Class and 0.3 for the Elite. 


\section{CONCLUSIONS}

First and foremost, we found an amazing geographic and historical stability in the patterns of seasonality in conceptions. Both Taiwan and the Netherlands had a different pattern, but this pattern remained the same although the countries underwent important social and economic changes. Remarkably, all occupational categories have the same pattern, except for the elite. As is often the case, we find the Rich and Ruling on the one hand and the Rest on the other hand. As far as cultural differences go, we find the expected differences in the Netherlands between Roman Catholics and Protestants, albeit that these differences are small and they do not change the general pattern. The Taiwanese Hakka and Hokkien couples also differed only marginally in conception seasonality. The most pervasive effect we could establish comes from a biological variable, namely temperature. The clear negative correlation between the number of conceptions and the temperature is striking. But then again, the months with the highest temperatures are also the so-called Ghost Months.

All this leads to an obvious conclusion: seasonality studies can inform us on many aspects of lives in the past, but the study of this phenomenon has only begun. As the findings above show, many conclusions are at best tentative. One conclusion is not tentative at all: both populations exhibit a seasonality pattern in conceptions that is so strong that economic and cultural variables only have a minor influence. The fact that a biological variable like temperature is so dominant in the Taiwanese case suggests that future studies may benefit from focusing on the biological determinants of human behaviour.

\section{REFERENCES}

Anderton, D. L., \& Barrett, R. E. (1990). Demographic seasonality and development: The effects of agricultural colonialism in Taiwan, 1906-1942. Demography, 27(3), 397-411. doi: 10.2307/2061375

Bobak, M., \& Gjonca, A. (2001). The seasonality of live birth is strongly influenced by socio-demographic factors. Human Reproduction, 16( 7), 1512-1517. doi: 10.1093/humrep/16.7.1512

Doblhammer, G, Rodgers, J. L., \& Rau, R. (2000). Seasonality of birth in nineteenth- and twentieth century Austria. Social Biology, 47(3-4), 201-217. doi: 10.1080/19485565.2000.9989019

Ellison, P. T., Valeggia, C., \& Sherry, D. S. (2005). Chapter 13 - Human birth seasonality. In D. K. Brockman \& C. P. van Schaik (Eds.), Seasonality in primates: Studies of living and extinct human and non-human primates (pp. 379-399). Cambridge: Cambridge University Press. doi: 10.1017/ CBO9780511542343.014

Fellman, J., \& Eriksson, A. W. (2009). Temporal and regional variations in the seasonality of births in Åland (Finland), 1653-1950. Biodemography and Social Biology, 55(1), 103-112. doi: $10.1080 / 19485560903054788$

Mandemakers, K. (2000). The Netherlands. Historical Sample of the Netherlands. In: P. K. Hall, R. McCaa, \& G. Thorvaldsen (Eds.). Handbook of international historical microdata for population research (pp. 149-177). Minneapolis: The Minnesota Population Center.

Manfredini, M. (2009). Birth seasonality in present-day Italy, 1993-2005. Human Ecology, 37, 227-234. doi: 10.1007/s10745-009-9221-x

Mosher, S. W. (1979). Birth seasonality among peasant cultivators: The interrelationship of workload, diet, and fertility. Human Ecology, 7(2), 151-181. doi: 10.1007/BF00917519

Régnier-Loilier, A. (2010). Changes in the seasonality of births in France from 1975 to the present. Population (E), 65(1), 145-185. doi: 10.3917/popu.1001.0147

Rojansky, N., Brzezinski, A., \& Schenker, J. G. (1992). Seasonality in human-reproduction: An update. Human Reproduction, 7(6), 735-745. doi: 10.1093/oxfordjournals. humrep.a137729

van Leeuwen, M. H. D., \& Maas, I. (2011). HISCLASS. A Historical Social Class Scheme. Leuven: Leuven University Press. 